\title{
Dialectics of Nature and Sustainable Development of Zhoushan Fishery
}

\author{
Ting Li \\ School of Economics and Management, Zhejiang Ocean University, Zhoushan, Zhejiang, 316022, China
}

\begin{abstract}
The composition and quantity distribution of fishery resources in Zhoushan fishery are very rich, and it is one of the fishery with the largest number of fishery species in the East China Sea. However, in recent years, due to the deterioration of the marine ecological environment and the overfishing of fishery resources, the fishery resources in Zhoushan have been gradually depleted. Fishery resources are natural resources, and they are interconnected and interact with nature. Therefore, we should look at the sustainable development of fishery from the perspective of dialectics, so as to realize the sustainable development of fishery in Zhoushan.
\end{abstract}

Keywords: Dialectics of nature, Sustainable development, Fishery.

\section{Research Background and Significance}

Zhoushan has a typical subtropical marine monsoon climate. The seabed in the coastal waters of the island is rugged and has many steep slopes. Due to the seasonal influence of the Jiangsu-Zhejiang coastal current, the Taiwan warm current and the cold water mass of the Yellow Sea, a relatively complex hydrological environment has been formed, which makes the fishery resources in this sea area. more abundant.

Zhoushan fishing ground is an important part of the East China Sea fishing ground. It is not only fertile water, but also rich in bait organisms, so it is a habitat for various fishery organisms to reproduce, feed, grow and overwinter. In history, Zhoushan fishery was once the fishery with the most abundant fishery biological resources in my country. There are many kinds of fishery creatures. However, due to the influence of various factors such as excessive fishing, severe fishing and environmental pollution, the traditional fishery biological resources in Zhoushan fishing grounds have been rapidly reduced, the main fishing objects have been frequently replaced, and a series of changes have taken place in the biological community structure. The fishing production of fishery resources in Zhoushan fishery and the stability of the ecosystem have had a major impact. Fishery biological resources play an important role and function in the sustainable development of marine ecosystems and marine fisheries. Therefore, we choose Zhoushan fishery for research and discuss the sustainable development strategy of Zhoushan fishery. This is a meaningful exploration of marine ecology and fishery management research, and provides a basis for the sustainable development of marine fisheries in Zhejiang Province.

\section{Research Method}

The research method used in this paper is the literature method. According to the relevant data collected from literature, publications and electronic databases, it is summarized and sorted, and then the Zhoushan fishery resources and environmental related materials are compared and analyzed, so as to summarize the connection between the dialectics of nature and the sustainable development of Zhoushan fishery.

\section{The Connection Between Dialectics of Nature and Sustainable Development of Fishery}

Dialectics of Nature is an important part of Marxist philosophy. It is a science about the general laws of the development of nature and natural sciences. It is an important theoretical weapon to guide people to understand nature, transform nature, coordinate the relationship between man and nature, and promote the development of science and technology. It is not only a dialectical materialist view of nature and a scientific view, but also a scientific methodology for understanding and transforming nature.

To realize the sustainable development of fishery is to protect the ecological environment of fishery from damage, protect fishery resources from being abused, realize the recycling and sustainable utilization of fishery resources, and promote the development of fishery and the income generation of fishermen. As an important method for people to understand and transform nature, dialectics of nature has important guiding significance for promoting the sustainable development of Zhoushan fishery.

\section{The Reasons for the Exhaustion of Fishery Resources in Zhoushan}

With the continuous exploration of the ocean by human beings, the living environment of fishery organisms has been occupied and destroyed, the marine environment has been seriously polluted, and human overfishing has led to serious decline of fishery biological resources, and a few fishery biological species have been close to exhaustion. The statistics of FAO in 2008 show that about $20 \%$ of the populations or species groups are under-exploited or moderately exploited, and about $52 \%$ of the main populations or species groups are in a fully exploited state. At or very close to their maximum sustainable limits, approximately nineteen percent of the populations or species groups are overexploited, and approximately nine percent are severely depleted or recovering. Most marine fisheries today are biologically mature early, and the average body length is reduced as a result of overfishing of fishery resources. 
Zhoushan fishery used to be the fishery with the most abundant fishery biological resources in my country. However, due to the influence of various factors such as indiscriminate fishing, severe fishing and ecological environment pollution, the traditional fishery biological resources of Zhoushan fishery decreased rapidly. The East China Sea fish warehouse is now "the East China Sea has no fish". This huge change has had a major impact on the fishing production of fishery resources in Zhoushan fisheries and the stability of the ecosystem. I think the main reasons for this are as follows:

(1) Zhoushan fishing grounds have many rivers entering the sea. The pollutants brought by the rivers and the pollutants and oil pollution directly discharged into the sea by some coastal enterprises have caused serious marine pollution in Zhoushan fishing grounds, and some fishery organisms cannot survive and reproduce normally.

(2) The perennial bottom trawling and other operations have caused serious damage to the ecological environment of the seabed. Repeated friction and scraping of the seabed have made the originally rich seabed animal and plant resources less and less, and the phenomenon of seabed desertification has occurred, which has directly led to some deep water. Layers of fish cannot survive and reproduce normally.

(3) Global warming has led to certain changes in seawater temperature, which has affected the reproduction and reproduction of some fish to a certain extent.

(4) Long-term indiscriminate fishing is the most direct and critical factor leading to the sharp decline of fishery biological resources. When the fishery resources in the Zhoushan fishery were still very rich, most fishing operations only required large and high-value fishery products, so some other by-catch that had been damaged by the nets would be thrown away directly. The original ecological structure had a very bad impact. The juveniles that are still developing are often killed because of this, and eventually fewer and fewer juveniles can grow into adults, while the original large adults have been caught, which has caused a serious decline in fishery resources.

\section{Suggestions on Promoting the Sustainable Development of Zhoushan Fishery}

In recent years, the marine ecological environment has been deteriorating and fishery resources have been depleted day by day. Zhejiang Province has put forward a sustainable development plan, issued a series of policies to protect the environment and fishery resources, and strictly implemented the fishing moratorium policy, so that the fishery resources and environment have gradually recovered. In this regard, I have a few suggestions, which I hope can help protect and improve the current situation of Zhoushan fishing grounds.

(1) Actively promote the establishment of marine ranches. The establishment of marine pastures is gradually promoted through specific measures such as proliferation and release and the construction of artificial reefs, so as to plan the stocking and proliferation of fishery resources in Zhoushan, so as to achieve the purpose of protecting fishery resources.
The concept of ocean ranch has been popularized very early, but it has not been paid attention to. Therefore, it is necessary for people to take active actions to promote the early realization of this concept.

(2) Standardize the management of marine vessel garbage and start pollution remediation projects. Domestic pollution from marine vessels as well as industrial pollutants must be dealt with in a regulated manner. Actively encourage the development of methods that can effectively treat pollutants, comprehensively carry out marine pollution control, and sewage treatment projects such as rivers and rivers. At the same time, the pollutant indicators of ships at sea are regulated, and corresponding punitive measures are adopted for ships that discharge pollutants into the sea in violation of regulations.

(3) Standardize the use of nets, and develop and design nets that can reduce by-catch. The use of bottom trawling nets and other nets that cause serious damage to the seabed environment should be reduced or even banned, and more new nets with less or no harm to the marine ecological environment should be developed. At the same time, relevant regulations are formulated to regulate the disposal of by-catch.

(4) Actively publicize marine conservation knowledge and let everyone participate. There are many fishermen in Zhoushan, and many fishermen's cultural and educational level is not high enough, so the awareness of marine protection is not enough. Therefore, the government should increase publicity efforts to let everyone participate in the ranks of marine protection. Let people realize that ocean protection is not something that is far away from themselves, and everyone can do their part by starting from trivial things like not throwing garbage into the sea on board.

\section{Conclusion}

Dialectics of nature is an important ideological weapon for human beings to transform nature and understand nature. We can combine the theory of dialectics of nature with the actual situation of Zhoushan to formulate a series of relevant management systems, which is of great guiding significance for the sustainable and healthy development of Zhoushan fishery. At this stage, an extremely important link in the development of Zhoushan's fishery is to accelerate the sustainable development of fishery, and we combine the dialectics of nature, which helps us to understand the law and development trend of Zhoushan's fishery development. Significance.

\section{References}

[1] Deng Jingyao, Zhao Chuanzhen, et al. Marine fishery biology[M]. Beijing: Agricultural Press, 1991: 25-27.

[2] Liu Weihai, Zhan Bingyi. Analysis of changes in fishery resources in the East China Sea[J]. Journal of Shanghai Fisheries University, 1999, 8(1): 19-24.

[3] Yu Cungen. Fishery ecology of Zhoushan fisheries[M]. Beijing: Science Press, 2011. 
[4] Shao Zhiyi. A historical exploration of the development of dialectics of nature[J]. Journal of Social Sciences of Jiamusi University, 2020, (5).

[5] Sun Molin. Sustainable development from the perspective of dialectics of nature[J]. Business Conditions, 2017, (20).

[6] Zhu He. On the dialectics of nature and the sustainable development of agriculture in China[J]. Rural Science and Technology, 2020, (6).

[7] Jia Jingde. Environmental protection is the top priority for the sustainable development of fisheries[J]. Freshwater Fisheries, 1997, (4).

[8] Bi Dingbang. Discussion on the sustainable development direction of Zhejiang fishery[J]. Modern Fishery Information, 1989, (C2).

[9] Wu Wanfu. On the sustainable development of marine fisheries[J]. Marine Fisheries, 1998, (1).

[10] W E Odum, E J Heald. The detritusbased food web of an estuarine mangrove community[J]. Estuarine Research, 1975, 1: 265-289

[11] FAO. The state of world fisheries and aquaculture[R]. United Nations Food and Agriculture Organization, 2008, 29-30.

[12] Shen C J. The crabs of Hong Kong[J]. Hong Kong Naturalist, 1931, (2): 92-110.

\section{Author Profile}

Ting Li (1996-), Graduate student at the School of Economics and Management, Zhejiang Ocean University. Born in Gansu, professional name agricultural management. 